\title{
Structural Evolution of Polyacrylonitrile Fibers in Stabilization and Carbonization
}

\author{
Sungho Lee ${ }^{1 *}$, Jihoon Kim ${ }^{1}$, Bon-Cheol Ku ${ }^{1}$, Junkyung Kim ${ }^{2}$, Han-Ik Joh ${ }^{1}$ \\ ${ }^{1}$ Institute of Advanced Composite Materials, Korea Institute of Science and Technology, \\ Jeollabuk-do, Korea (South) \\ ${ }^{2}$ Korea Institute of Science and Technology, Seoul, Korea (South) \\ Email: *sunghol@kist.re.kr
}

Received January 26, 2012; revised February 25, 2012; accepted March 31, 2012

\begin{abstract}
The effect of structural evolution polyacrylonitrile (PAN) on mechanical properties was investigated in stabilization and carbonization. PAN spun fibers were stabilized in a convection oven with a constant tension for various times at $250^{\circ} \mathrm{C}$. Fourier Transform Infrared spectroscopy (FTIR) and gel fraction results suggested that intra and intermolecular stabilization reactions occurred simultaneously. X-ray diffractograms revealed a disruption of crystalline structure and an appearance of pre-graphitic structure of PAN fibers due to stabilization. These structural changes by stabilization resulted in the significant decrease of tensile properties of fibers. In Raman spectra with heat treated fibers from $400^{\circ} \mathrm{C}$ up to $1200^{\circ} \mathrm{C}$, the intensity ratio of the $\mathrm{D}$ to $\mathrm{G}$ bands $\left(\mathrm{I}_{\mathrm{D}} / \mathrm{I}_{\mathrm{G}}\right)$ decreased as heat treatment temperature increased, indicating an increase of basal plane of graphitic layer of heat treated fibers. Tensile strength of heat treated fibers at $1200^{\circ} \mathrm{C}$ was found to be as high as $2.2 \mathrm{GPa}$.
\end{abstract}

Keywords: Polyacrylonitrile; Stabilization; Carbonization; XRD; Tensile Properties; Carbon Fibers

\section{Introduction}

Carbon fibers are manufactured from three precursor materials such as rayon polyacrylonitrile (PAN), and mesophase pitch. Rayon was the first precursors for commercialized carbon fibers (CF) [1,2]. Due to low productivity of rayon-based $\mathrm{CF}$, PAN and mesophase pitch have been more preferred. However, mesophase pitch-based CFs are inferior to PAN-based CF in tensile strength [1]. Furthermore, the difficulty of mesophase pitch synthesis with a high average molecular weight with no or small side groups required for melt spinning process is another drawback. Therefore, PAN has been most widely used materials for carbon fiber precursors for more than thirty years. Approximately $90 \%$ of CFs produced in the world is PAN-based CF $[1,3]$.

To produce $\mathrm{PAN}-$ based $\mathrm{CFs}$, three stages are required: wet spinning, stabilization, and carbonization. Stabilization of PAN is performed by heating from $200^{\circ} \mathrm{C}$ to $300^{\circ} \mathrm{C}$ in air under tension, leading to cyclization, dehydrogenation, and oxidation. PAN molecules are cyclized to transform into a non-meltable ladder structure, which is critical to avoid melting during carbonization [4]. It is known that nitrile groups in PAN are initiated thermally through a free radical mechanism, leading to cyclized

"Corresponding author. network of hexagonal carbon-nitrogen rings [5]. Further, the nitrile groups in PAN with a large dipole provide high cohesive energy density and chain stiffness, which result in excellent tensile strength [6]. Commercially, PAN precursors are polymerized with acidic comonomers such as acrylic acid, methacrylic acid, and itaconic acid [5]. Stabilization is one of the most important factors to determine mechanical strength of PAN based carbon fibers. Fitzer et al. reported optimization of stabilization of PAN fibers and effect of carbonization of resulting fibers on tensile strength [4]. Even though stabilization of PAN fibers has been studied for more than thirty tears, the exact mechanism and the structure of stabilized PAN fiber are unknown.

In this study, a systematic study on the stabilization and carbonization of PAN fibers was reported to investigate the change of structure and properties. PAN fibers were wet spun and stabilized for various duration times. Evolution of the extent of stabilization was observed using Fourier Transform Infrared spectroscopy (FT-IR). Thermal behavior of the stabilized PAN fibers was observed by differential scanning calorimetry (DSC) and thermogravimetry (TGA). To investigate structure, $\mathrm{X}$-ray diffraction was used. Furthermore, structural change of fibers during carbonization was observed using X-ray diffraction and Raman spectroscopy. Tensile test of the 
stabilized and carbonized fibers were performed.

\section{Experimental}

Commercial PAN was obtained from Sigma-Aldrich. Molecular weight was found to be $\sim 100,000 \mathrm{~g} / \mathrm{mol}$ by HLC8320GPC (TOSOH, Japan). A lab scale spinning line was developed [7]. A spinneret with one hundred fifty holes was mounted for wet spinning at $20^{\circ} \mathrm{C}$. A diameter of each hole was $0.1 \mathrm{~mm}$. A wet spinning line had four baths: one coagulation bath and three washing baths. The coagulation bath contained DMSO/distillated water $(=5: 5)$ mixture at $20^{\circ} \mathrm{C}$, and three washing baths were operated with distillated boiling water. After spinning, fibers were dried in a convection oven for 2 days at $60^{\circ} \mathrm{C}$.

Stabilization of fibers was performed in a convection oven at $250^{\circ} \mathrm{C}$ for various duration times $(5-180 \mathrm{~min})$. A constant tension was applied to fiber tows during stabilization. Gel fractions of the stabilized fibers were measured after equilibrium swelling (7 days) in dimethyl sulphoxide (DMSO) solvent (Aldrich Chemical Company, Inc. Milwaukee, WI). Mixtures were filtered to remove DMSO. Then, the remaining gels were dried in vacuum oven at $50^{\circ} \mathrm{C}$ for 7 days. Gel fraction was obtained using the mass ratio of the remainings to original fibers. Heat treatment of stabilized fibers under nitrogen atmosphere was performed using a tubular furnace (Korea Furnace Development Co. Ltd., Korea). After fiber loading, the temperature increased to a set point of $400^{\circ} \mathrm{C}-1200^{\circ} \mathrm{C}$ at a rate of $5^{\circ} \mathrm{C} / \mathrm{min}$, and fibers were cooled down without hold.

Fourier Transform Infrared spectroscopy (FTIR) spectra were obtained using a Nicolet iS10 FTIR spectrometer (Thermo Scientific, USA) in a range of $400-4000$ $\mathrm{cm}^{-1}$ with an Attenuated Total Reflectance (ATR) mode. Stabilized fibers were heated up to $500^{\circ} \mathrm{C}$ in an air or nitrogen atmosphere at a rate of $10^{\circ} \mathrm{C} / \mathrm{min}$ for studying the effect of stabilization time on thermal behaviors using a differential scanning calorimetry (DSC) Q20 (TA Instrument, USA). Thermogravimetric analysis (TGA) was performed in a nitrogen atmosphere with a rate of $20^{\circ} \mathrm{C} / \mathrm{min}$ using a TGA Q50 (TA Instrument, USA). $\mathrm{X}$-ray diffractometer (XRD, Rigaku D/Max2500H, Japan) of $\mathrm{Cu} \mathrm{K} \alpha$ radiation $(\lambda=1.5406 \AA$ ) was used over the $2 \theta$ range of $10^{\circ}$ to $50^{\circ}$ to observe structural change during stabilization and heat treatment. Raman spectroscopy was performed using LabRAM HR system (Horiba Jobin Yvon, France) with $16 \mathrm{~mW}$ and $633 \mathrm{~nm}$ laser for heat treated fibers. All the spectra were obtained over a spectral range of $500-3000 \mathrm{~cm}^{-1}$.

For tensile testing, a single fiber was loaded to a paper tab with a $25 \mathrm{~mm}$ gauge length. An epoxy resin was applied to both ends of fibers, and cured for $24 \mathrm{hr}$ at $50^{\circ} \mathrm{C}$.
Fiber diameters were measured by an optical microscope (Olympus BX51, Japan). The tensile properties were determined using an Instron Universal Tester 5567 (Instron, USA) at $25^{\circ} \mathrm{C}$. The crosshead speed was 5 $\mathrm{mm} / \mathrm{min}$ for all specimens, and twenty replicates were tested at each condition.

\section{Results and Discussion}

\subsection{FTIR Analysis of Stabilized PAN Fibers}

Figure 1 shows FTIR spectra of PAN fibers before and after stabilization in a convection oven at $250^{\circ} \mathrm{C}$ with various times. Before stabilization, distinct absorption bands appeared at 2939, 2243, 1454, and $1360 \mathrm{~cm}^{-1}$ assigned to $v_{\mathrm{C}-\mathrm{H}}$ in $\mathrm{CH}_{2}, v_{\mathrm{C} \equiv \mathrm{N}}$ in $\mathrm{CN}, \delta_{\mathrm{C}-\mathrm{H}}$ in $\mathrm{CH}_{2}$, and $\delta_{\mathrm{C}-\mathrm{H}}$ in $\mathrm{CH}$, respectively (Figure 1(a)). A band at $1071 \mathrm{~cm}^{-1}$ resulted from $\mathrm{S}=\mathrm{O}$ groups of DMSO solvent, which were remained after spinning [8]. There was no significant change with stabilized fibers for 5 and 10 min (Figures 1(b) and (c)). Stabilized fibers for $30 \mathrm{~min}$ showed an appearance at $1595 \mathrm{~cm}^{-1}$ assigned to conjugated $\mathrm{C}=\mathrm{N}$ stretching with a little intensity (Figure 1(d)). With stabilized fibers for $60 \mathrm{~min}$, a band at $1595 \mathrm{~cm}^{-1}$ became bigger, but intensities of bands at 2939, 2243, and 1454 $\mathrm{cm}^{-1}$ decreased, resulting from the cyclization and dehydrogenation of fibers (Figure 1(e)). For $120 \mathrm{~min}$, two shoulders appeared at 1710 and $1660 \mathrm{~cm}^{-1}$ (Figure 1(f)).

Shimada and Takahagi reported that these shoulders are assigned to the free ketones in hydronaphthyridine rings and the conjugated ketones in acridone rings, resulting from the oxygen uptake reaction $[9,10]$. Furthermore, a new small band at $2200 \mathrm{~cm}^{-1}$ was observed with stabilized fibers. It is reported that the band is assigned to the $\alpha, \beta$-unsaturated nitrile groups due to hydrogenation, or tautomerization and isomerisation of the ladder polymer [11,12]. In Figure 1(g), it is interesting that the band and shoulder at 2243 and $1454 \mathrm{~cm}^{-1}$, respectively, are distinct. This reveals that all PAN are not cyclized even after stabilization for $180 \mathrm{~min}$ at $250^{\circ} \mathrm{C}$.

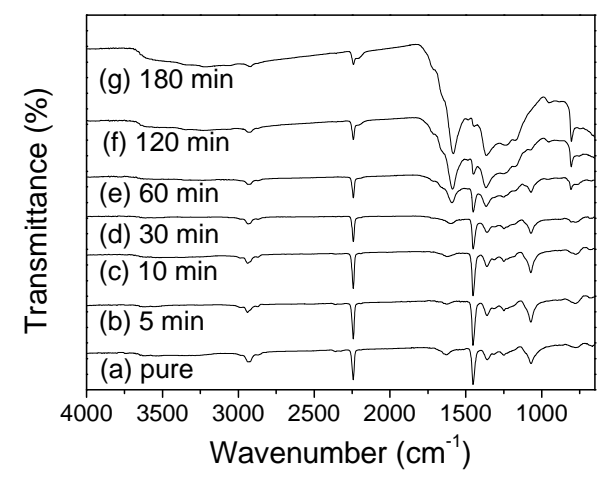

Figure 1. FT-IR spectra of (a) PAN fiber and its stabilized fibers at $250^{\circ} \mathrm{C}$ for: (b) $5 \mathrm{~min}$; (c) $10 \mathrm{~min}$; (d) $30 \mathrm{~min}$; (e) 60 min; (f) $120 \mathrm{~min}$; and (g) $180 \mathrm{~min}$. 
The degree of stabilization or extent of reaction (EOR), which ranges from 0 to 1 for no stabilization to complete stabilization, was quantified using the intensity of the peak at 1595 and $2243 \mathrm{~cm}^{-1}$ assigned to $\mathrm{C}=\mathrm{N}$ and $\mathrm{C} \equiv \mathrm{N}$, respectively, in FTIR spectra $\left[\mathrm{EOR}=\mathrm{I}_{1595} /\left(\mathrm{I}_{1595}+\mathrm{I}_{2243}\right)\right]$ [13]. As expected, the longer stabilization time led to the higher EOR value in Figure 2. 0 to 0.91 with stabilized fibers for 5 to $180 \mathrm{~min}$.

Gel fraction test of Pure PAN and its stabilized fibers was performed. As expected, pure PAN fibers were dissolved in DMSO and gel was not observed. However, gel contents of stabilized fibers for 5 and 10 min were 50 and $100 \%$. Furthermore, stabilized fibers for more than 10 min did not dissolved in DMSO for 7 days. Gupta and Harrison studied stabilization of co-polymer PAN as temperature increased up to $380^{\circ} \mathrm{C}$ with a heating rate of $1{ }^{\circ} \mathrm{C} / \mathrm{min}$, and claimed intramolecular cyclization and intermolecular cross-linking reactions took place in amorphous and crystalline regions at a different temperature range [14]. According to their report, intramolecular cyclization reactions started in amorphous and crystalline region at $175^{\circ} \mathrm{C}$ and $\sim 215^{\circ} \mathrm{C}$. As temperature increased, intermolecular cross-linking reactions initiated in amorphous and crystalline region at $\sim 300^{\circ} \mathrm{C}$.

Stabilized fibers for $10 \mathrm{~min}$ developed yellow from white of pure PAN fibers, which indicates that fibers were not stabilized enough. Furthermore, it is interesting to note that FTIR results showed no significant change of spectra with stabilized fibers for $10 \mathrm{~min}$, compared to pure PAN fibers. In our stabilization temperature $\left(250^{\circ} \mathrm{C}\right)$, it is likely that intermolecular cross-linking reactions happened even though intramolecular cyclization was not completed. This suggests that intra and intermolecular stabilization reactions occurred simultaneously.

\subsection{Thermal Behavior of Stabilized PAN Fibers}

The stabilization of PAN fibers was investigated using non-isothermal DSC analysis. The first heating thermograms at a rate of $10^{\circ} \mathrm{C} / \mathrm{min}$ in $\mathrm{N}_{2}$ atmosphere are dis-

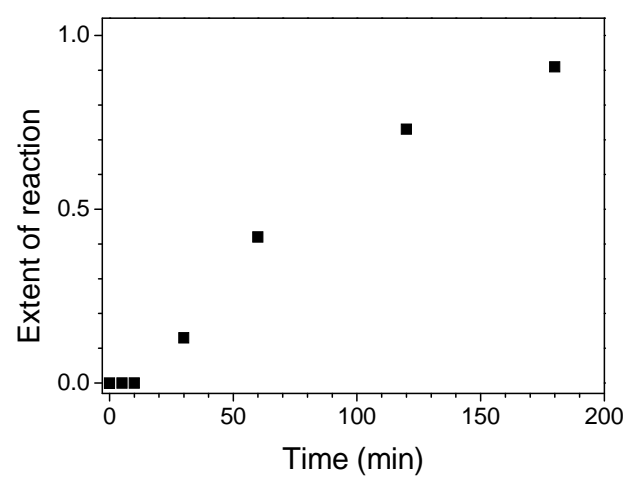

Figure 2. Extent of reaction $\left(E O R=I_{1595} /\left(I_{1595}+I_{2243}\right)\right)$ as a function of stabilization time at $250^{\circ} \mathrm{C}$. played in Figure 3. The cyclization temperature $\left(\mathrm{T}_{\mathrm{c}}\right)$ and $\left(\Delta \mathrm{H}_{\mathrm{c}}\right)$ were summarized in Table 1 . The PAN fibers before stabilization showed one cyclization peak at $294.6^{\circ} \mathrm{C}$. An onset temperature was $280.6^{\circ} \mathrm{C}$, and the curves completed at $307.4^{\circ} \mathrm{C}$ (Figure 3(a)). It is known that compared to itaconic acid modified PAN, which can have two separated peaks due to ionic and free radical mechanism, pure PAN fiber is cyclized only by a free radical mechanism, revealing one peak [15]. The similar peaks were observed with stabilized fibers for 5 and $10 \mathrm{~min}$. However, the peak with stabilized fibers for $30 \mathrm{~min}$ was shifted to higher temperature $\left(307^{\circ} \mathrm{C}\right)$. Compared to unstabilized fibers, the heat of reaction decreased from 520 $\mathrm{J} / \mathrm{g}$ to $474 \mathrm{~J} / \mathrm{g}$, which indicates that PAN molecules were stabilized for $30 \mathrm{~min}$ in a convection oven. As stabilized time goes longer, the peak was broader with a higher cyclization temperature. Furthermore, heat of the cyclization became smaller in Figure 3(g), and it is evident that the stabilization for 180 min led to a significant degree of cyclization, which is consistent with FTIR results. It should be noted that the DSC thermograms in Figure

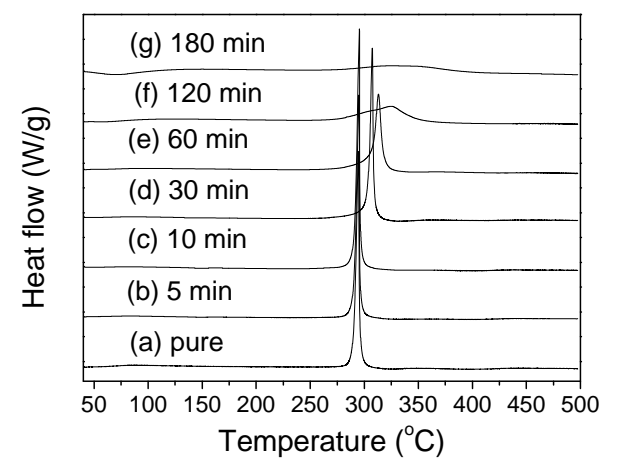

Figure 3. Non-isothermal DSC thermograms (nitrogen atmosphere) of (a) PAN fiber and its stabilized fibers at $250^{\circ} \mathrm{C}$ for: (b) $5 \mathrm{~min}$; (c) $10 \mathrm{~min}$; (d) $30 \mathrm{~min}$; (e) $60 \mathrm{~min}$; (f) 120 min; and (g) $180 \mathrm{~min}$.

Table 1. The cyclization temperatures $\left(T_{c}\right)$ and heats of cyclization $\left(\Delta \mathbf{H}_{c}\right)$ measured by DSC in nitrogen and air for PAN fiber and its stabilized fibers for various time at $250^{\circ} \mathrm{C}$.

\begin{tabular}{cccc}
\hline $\begin{array}{c}\text { Stabilization } \\
\text { time (min) }\end{array}$ & $\mathrm{T}_{\mathrm{c}}\left({ }^{\circ} \mathrm{C}\right)$ in $\mathrm{N}_{2}$ & $\Delta \mathrm{H}_{\mathrm{c}}(\mathrm{J} / \mathrm{g})$ in $\mathrm{N}_{2}$ & $\mathrm{~T}_{\mathrm{c}}\left({ }^{\circ} \mathrm{C}\right)$ in air \\
\hline 0 & 294.6 & 520 & 321.7 \\
5 & 295.2 & 518 & 320.4 \\
10 & 295.6 & 520 & 319.9 \\
30 & 307.4 & 474 & 319.6 \\
60 & 313.1 & 423 & 318.9 \\
120 & 327.7 & 328 & - \\
180 & - & 238 & - \\
\hline
\end{tabular}


3 were obtained in $\mathrm{N}_{2}$ atmosphere, which indicates that only heat initiated all exothermic reactions without oxygen. Hence, an oxidative reaction took place in a convection oven results in decrease of heat of the cyclization in the DSC thermograms. Furthermore, the partially cyclized PAN fibers revealed a higher cyclization temperature than did pure PAN fibers, suggesting that more thermal energy is needed for cyclization of the rest of unreacted PAN fibers.

The non-isothermal DSC analysis was also performed in an air atmosphere in Figure 4. Heat of the cyclization $\left(\Delta \mathrm{H}_{\mathrm{c}}\right)$ was not calculated since we could not suggest an accurate method to make a base line practically due to the shape of the DSC thermograms, rendering a strong intensity difference in both sides of curves. Figure 4(a) represents the thermogram of pure PAN fibers before stabilization with one peak at $321.7^{\circ} \mathrm{C}$. It is interesting to note that the peak is at higher temperature compared to the DSC thermograms in nitrogen atmospheres $\left(294.6^{\circ} \mathrm{C}\right.$ in Figure 3(a)). The curve after peak was not back to an original base line, which was not observed with the thermograms in nitrogen (Figure 3(a)). Similar thermograms were reported in an air atmosphere, but there was no clear explanation [4]. We believed that heat capacity difference between PAN fibers and corresponding oxidized PAN fibers resulted in heat flow difference in DSC thermograms. Stabilized fibers for 5, 10 and $30 \mathrm{~min}$ in Figures 4(b), (c) and (d), respectively, showed a peak at $320.4^{\circ} \mathrm{C}, 318.9^{\circ} \mathrm{C}$, and $319.9^{\circ} \mathrm{C}$ with a similar intensity. The peak became smaller with 60 min of stabilization time. As stabilization time increased, even the peak disappeared (Figures $\mathbf{4 ( f )}$ and (g)).

Figure 5 represents TGA analysis of PAN and its stabilized fibers with a ramp of $20^{\circ} \mathrm{C} / \mathrm{min}$ in $\mathrm{N}_{2}$ atmosphere before and after stabilization. PAN fibers before stabilization showed four stages of weight change (Figure 5(a)). In the first stage up to $295^{\circ} \mathrm{C}$, there was no weight loss. However, $\sim 35 \%$ of weight loss from $295^{\circ} \mathrm{C}$ to $325^{\circ} \mathrm{C}$ was

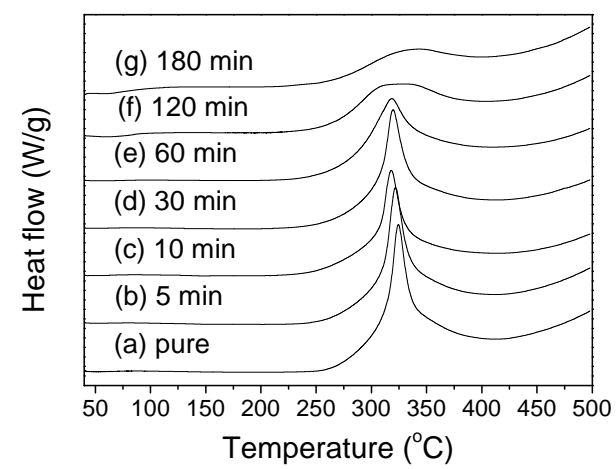

Figure 4. Non-isothermal DSC thermograms (air atmosphere) of (a) PAN fiber and its stabilized fibers at $250^{\circ} \mathrm{C}$ for: (b) $5 \mathrm{~min}$; (c) $10 \mathrm{~min}$; (d) $30 \mathrm{~min}$; (e) $60 \mathrm{~min}$; (f) $120 \mathrm{~min}$; and (g) $180 \mathrm{~min}$.

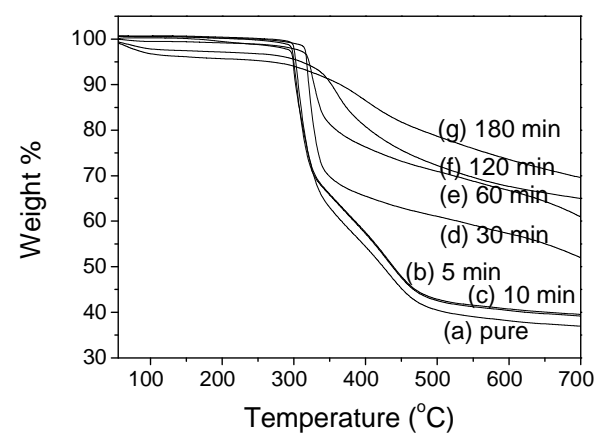

Figure 5. TGA thermograms (nitrogen atmosphere) of (a) PAN fiber and its stabilized fibers at $250^{\circ} \mathrm{C}$ for: (b) $5 \mathrm{~min}$; (c) $10 \mathrm{~min}$; (d) $30 \mathrm{~min}$; (e) $60 \mathrm{~min}$; (f) $120 \mathrm{~min}$; and (g) 180 min.

observed in the second stage, indicating that a significant chemical reaction took place, and volatile gases came out [16]. It is recalled that cyclization peak temperature was at $294.6^{\circ} \mathrm{C}$ in a DSC thermogram (Figure 3(a)). A further decrease of weight ( $65 \%$ to $40 \%)$ was found from $325^{\circ} \mathrm{C}$ to $480^{\circ} \mathrm{C}$ in the third stage. In the last stage up to $700^{\circ} \mathrm{C}$, a monotonous decrease of weight was observed with a total weight loss of $\sim 63 \%$.

Compared to pure PAN fiber, a small decrease of weight in the second stage was observed with stabilized fibers for 5 and $10 \mathrm{~min}$ (Figure 5(b) and (c)). Stabilized PAN fibers for 30 min showed a higher on-set temperature of sudden decrease and a lower weight loss (Figure 5(c)). A weight decrease started at $312^{\circ} \mathrm{C}$, and $\sim 33 \%$ of weight loss was found at $340^{\circ} \mathrm{C}$. Cyclization peak temperature of stabilized fibers for $30 \mathrm{~min}$ was observed at $307.4^{\circ} \mathrm{C}$ in a DSC thermogram (Figure 3(c)). Furthermore, there was not a significant weight change observed with stabilized fibers from $325^{\circ} \mathrm{C}$ to $700^{\circ} \mathrm{C}$, leading to three stages. A further weight loss of $\sim 15 \%$ was completed at $700^{\circ} \mathrm{C}$. Similar curves stabilized fibers for 60 and 120 min were observed with a total weight loss of $\sim 33 \%$ and $\sim 38 \%$, respectively (Figures 5(e) and (f)). As stabilization time increased, it is likely that there are two stages with a decreased total weight loss as expected. PAN fiber stabilized for $180 \mathrm{~min}$ showed $28 \%$ of weight loss at $700^{\circ} \mathrm{C}$ (Figure 5(g)). This indicated that a little amount of PAN was remained for the further reaction after stabilization at a low temperature region.

\subsection{X-Ray Diffraction Analysis of Stabilized PAN Fibers}

The integrated azimuthal profiles ( $2 \theta$ scans) of pure PAN and its stabilized fibers are displayed in Figure 6. For pure PAN fibers, the peak associated with (100) plane of a hexagonal structure appeared at $2 \theta$ values of $\sim 17^{\circ}$ [17]. Another peak with a small intensity was observed at $2 \theta$ of $\sim 29.3^{\circ}$. Up to $60 \mathrm{~min}$ stabilization, no significant change 


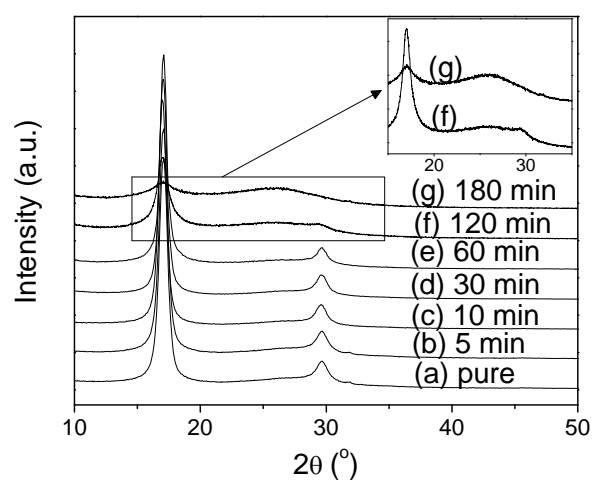

Figure 6. The integrated azimuthal profiles ( $2 \theta$ scans) of (a) PAN fiber and its stabilized fibers at $250^{\circ} \mathrm{C}$ for: (b) $5 \mathrm{~min}$; (c) $10 \mathrm{~min}$; (d) $30 \mathrm{~min}$; (e) $60 \mathrm{~min}$; (f) $120 \mathrm{~min}$; and (g) 180 min. The inset profiles are the enlarged $2 \theta$ scans for (f) and (g).

was found. For stabilized fibers for $120 \mathrm{~min}$, an intensity of two peaks became low, indicating the disruption of orientation and crystalline structure by thermal stabilization. Furthermore, a peak at $2 \theta$ of $\sim 25.6^{\circ}$ appeared. This peak is more distinct with stabilized fibers for 180 min, which showed a very small peak at $2 \theta$ of $\sim 17^{\circ}$ and disappearance of the peak at $2 \theta$ of $\sim 29.3^{\circ}$. Mathur et al. reported that a broad peak at $2 \theta=25.5^{\circ}$ appeared with prolonged stabilization, associated with the (002) planes of the pre-graphitic structure [17]. Therefore, it is evident in Figure 6(g) that an original PAN structure changed by stabilization.

\subsection{Tensile Properties of Stabilized PAN Fibers}

Figure 7 displays tensile properties of PAN and its stabilized fibers. Tensile strength of PAN fibers without stabilization was $\sim 0.5 \mathrm{GPa}$ (Figure 7(a)). Stabilized PAN fibers for up to $30 \mathrm{~min}$ showed no significant change of tensile strength. A further increase of stabilization time led to a monotonous decrease of tensile strength, and tensile strength of $\sim 0.23 \mathrm{GPa}$ was observed with stabilized PAN fibers for $120 \mathrm{~min}$. No further decrease was found. In Figure 7(b), tensile moduli were shown for PAN and its stabilized fibers. As stabilization time increased, a change of tensile modulus was not significant: 13.5 and $12.4 \mathrm{GPa}$ for PAN and stabilized fibers for $180 \mathrm{~min}$, respectively.

It is recalled that FTIR spectra of stabilized fibers for $120 \mathrm{~min}$ showed the significant degree of cyclization $(\mathrm{EOR}=0.73$ in Figure 2). Furthermore, X-ray diffratograms showed the structural change of PAN fibers. It is likely that mechanical properties of stabilized fibers such as tensile strength were determined by structure. It is suggested that the ladder structure of stabilized fibers resulted in less tensile strength compared to pure PAN fibers due to disruption of orientation and crystalline structure by thermal stabilization. Strain-to-failure of PAN fibers in Figure 7(c) was found to be 11\%, but fibers stabilized for 5 min showed strain-to-failure of $18 \%$ due to relaxation of PAN fibers during stabilization even though a constant tension was applied. Stabilized fiber for $30 \mathrm{~min}$ showed the value of $14 \%$. Up to stabilization time of $180 \mathrm{~min}$, strain-to-failure decreased down to $7 \%$. This is consistent to the result by Gupta and Harrison [18]. They reported that a decrease of strain-to-failure was attributed to intermolecular cross-linking reactions to lead to a network formation.

\subsection{Heat Treatment of Stabilized PAN Fibers}

Stabilized fibers for $180 \mathrm{~min}$ were heat treated at various temperatures from 400 up to $1200^{\circ} \mathrm{C}$. The integrated azimuthal profiles ( $2 \theta$ scans) of heat treated fibers are displayed in Figure 8. The peak associated with (100) plane of pure PAN at $2 \theta$ of $\sim 17^{\circ}$ disappeared with all heat treated fibers (Figure 6). Furthermore, a peak at $2 \theta$ of $\sim 25.6^{\circ}$ with stabilized fibers was shifted to $2 \theta$ of $\sim 25.2^{\circ}$ for heat treated fibers at $400^{\circ} \mathrm{C}$. This peak associated with (002) plane was not significantly changed with heat treated fibers at higher temperature up to $1200^{\circ} \mathrm{C}$. In Figure 8(g), X-ray diffractogram of PAN based commercial carbon fibers (T-300, Toracaya Co., Ltd. Japan) showed a peak at $2 \theta$ of $\sim 25.2^{\circ}$, indicating that our heat treated fibers are similar to turbostratic carbon structure of T-300

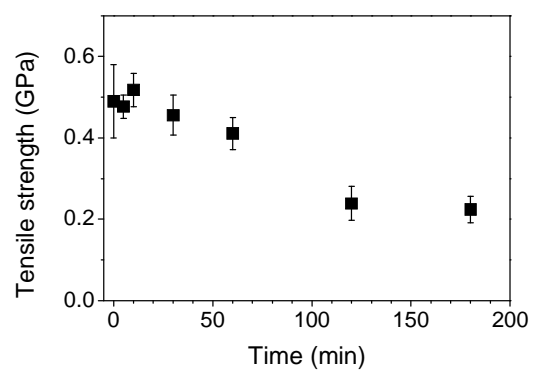

(a)

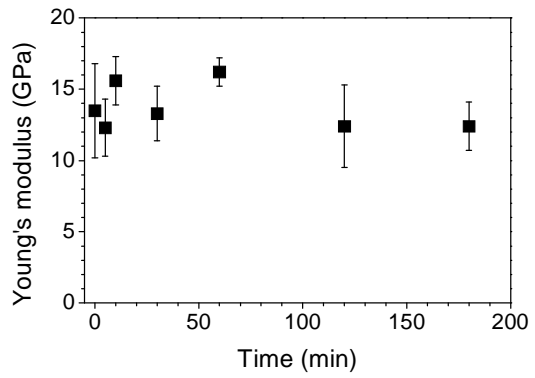

(b)

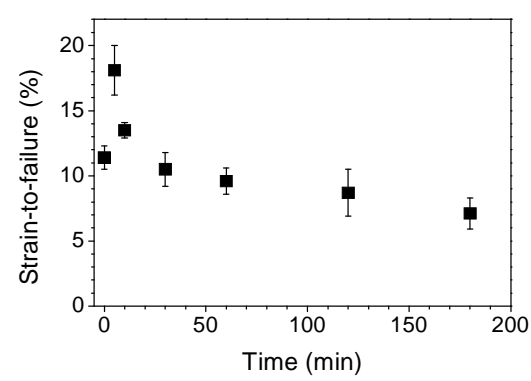

(c)

Figure 7. Tensile properties of PAN fiber and its stabilized fibers: (a) Tensile strength; (b) Tensile modulus; and (c) Strainto-failure as a function of stabilization time. 
fibers [19]. Figure 9 represents Raman spectra of heat treated fiber and T-300 carbon fibers. A weak shoulder at $\sim 1190 \mathrm{~cm}^{-1}$ and two peaks at $\sim 1340 \mathrm{~cm}^{-1}$ and $\sim 1580$ $\mathrm{cm}^{-1}$ were observed for all fibers. A broad peak around $1150-1200 \mathrm{~cm}^{-1}$ is associated with functional groups such as $\mathrm{C}=\mathrm{O}$ [20]. Thus, a shoulder at $\sim 1200 \mathrm{~cm}^{-1}$ observed for all fibers can be inferred as functional groups obtained during stabilization. For carbon fibers, the D and $\mathrm{G}$ band at $1360 \mathrm{~cm}^{-1}$ and $1600 \mathrm{~cm}^{-1}$ are attributed to structural disorder within graphite planes and the graphitic crystalline structure, respectively [21]. Furthermore, a broad peak around $1500-1550 \mathrm{~cm}^{-1}$ was observed with heat treated fibers and T-300 carbon fibers, indicating high contents of amorphous carbon [21]. From Raman spectra, the intensity ratio of the $\mathrm{D}$ to $\mathrm{G}$ bands $\left(\mathrm{I}_{\mathrm{D}} / \mathrm{I}_{\mathrm{G}}\right)$ was calculated to be $2.17,1.98,1.72,1.64,1.43$, and 1.48 for heat treated fibers at $400,600,800,1000,1200^{\circ} \mathrm{C}$, and T-300 fibers, respectively. The value decreased as heat treatment temperature increased, indicating an increase of basal plane of graphitic layers in heat treated fibers. It is evident that even though turbostratic structure is dominant with amorphous carbon in our fibers, the heat treatment led to the development of graphene layers.

Tensile test was performed for heat treated fibers to investigate the effect of heat treatment on mechanical properties of stabilized fibers. In Figure 10(a), tensile strength and modulus with fibers heat treated at $400^{\circ} \mathrm{C}$ were found to be $308 \pm 33 \mathrm{MPa}$ and $17 \pm 3 \mathrm{GPa}$, respectively. A gradual increase of tensile strength and modulus was observed as temperature increased up to $800^{\circ} \mathrm{C}$ (Figures 10(a) and (b)). However, the values were significantly increased with heat treatment at $1000^{\circ} \mathrm{C}$, and tensile strength and modulus with fibers heat treated at $1200^{\circ} \mathrm{C}$ were found to be $2219 \pm 228 \mathrm{MPa}$ and $215 \pm$ $36 \mathrm{GPa}$, respectively. As expected, tensile strain decreased from $4.9 \%$ to $0.9 \%$ for heat treated fibers at 400 and $1200^{\circ} \mathrm{C}$, respectively (Figure $10(\mathbf{c})$ ). Fitzer et al. observed volatile gases produced during heat treatment [4]. $\mathrm{HCN}$ was dominant at below $700^{\circ} \mathrm{C}$ with other gases such as $\mathrm{CO}_{2}, \mathrm{CO}$, and $\mathrm{H}_{2} \mathrm{O}$. Furthermore, $\mathrm{N}_{2}$ was a main volatile byproduct at above $700^{\circ} \mathrm{C}$. They reported that such a gas release was a subsequent effect of heat treatment to develop graphitic structure. Tensile strength in Figure 10 is consistent with their results so that a significant increase was observed with fibers heat treated at above $1000^{\circ} \mathrm{C}$. This supports the development of graphene layers observed in Raman spectra. It is recalled that the peak of (002) plane in X-ray diffratograms did not change as heat treatment temperature increased. This suggests that temperature up to $1200^{\circ} \mathrm{C}$ is not high enough to result in reducing the interlayer spacing $\left(\mathrm{d}_{002}\right)$ significantly. However, tensile strength of the resulting

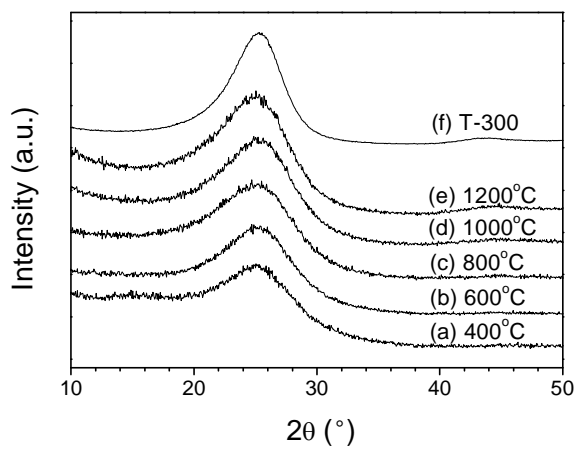

Figure 8. The integrated azimuthal profiles ( $2 \theta$ scans) of heat treated fibers at (a) $400^{\circ} \mathrm{C}$; (b) $600^{\circ} \mathrm{C}$; (c) $800^{\circ} \mathrm{C}$; (d) $1000^{\circ} \mathrm{C}$; (e) $1200^{\circ} \mathrm{C}$; and (f) $\mathrm{T}-300$ carbon fibers.

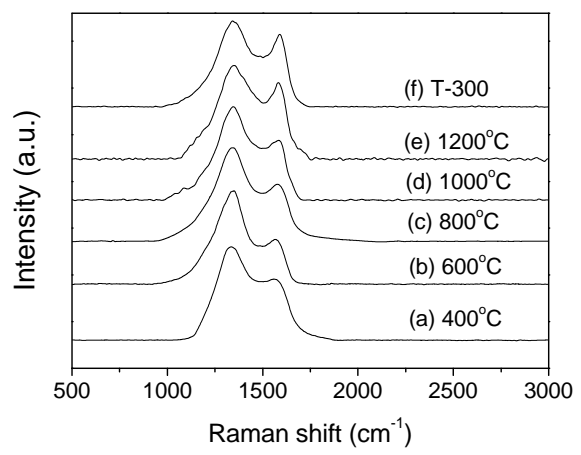

Figure 9. Raman spectra of heat treated fibers at (a) $400^{\circ} \mathrm{C}$; (b) $600^{\circ} \mathrm{C}$; (c) $800^{\circ} \mathrm{C}$; (d) $1000^{\circ} \mathrm{C}$; (e) $1200^{\circ} \mathrm{C}$; and (f) $\mathrm{T}-300$ carbon fibers.

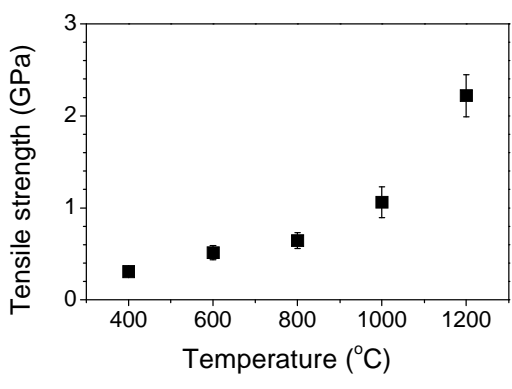

(a)

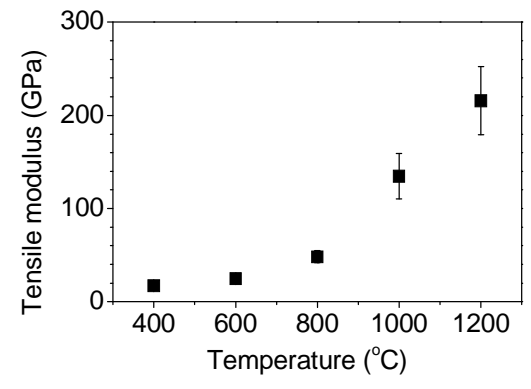

(b)

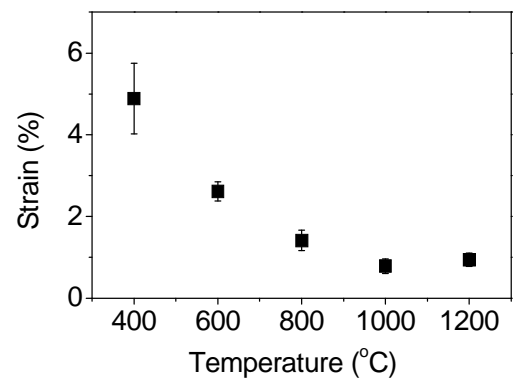

(c)

Figure 10. Tensile properties of heat treated fibers: (a) Tensile strength; (b) Tensile modulus; and (c) Strain-to-failure as a function of carbonization temperature. 
carbon fibers was as high as $2.2 \mathrm{GPa}$.

\section{Conclusion}

Polyacrylonitrile (PAN) fibers were spun using the lab scale wet spinning line. Fibers were stabilized in a convection oven with a constant tension for various times at $250^{\circ} \mathrm{C}$. FT-IR spectra of stabilized fibers indicated cyclization of PAN fibers to form a network structure. FTIR and gel fraction results suggested that intra and intermolecular stabilization reactions occurred simultaneously. As expected, the longer stabilization time led to the higher extent of reaction (EOR) value: 0 to 0.91 with stabilized fibers for 5 to $180 \mathrm{~min}$. Non-isothermal DSC analysis of PAN and its stabilized fibers in nitrogen exhibited evolution of cyclization as a function of stabilization time. A longer stabilization time led to a smaller heat of cyclization and broader thermograms. TGA analysis of PAN fibers showed a dramatic decrease of weight from $295^{\circ} \mathrm{C}$ to $325^{\circ} \mathrm{C}$, where the cyclization peak was found in DSC thermograms. This indicated that volatile gases came out due to a strong exothermic reaction. However, such a decrease was not observed with stabilized fibers for 120 and $180 \mathrm{~min}$ at $250^{\circ} \mathrm{C}$ since a little amount of PAN was remained for the reaction. X-ray diffractograms revealed a disruption of crystalline structure and an appearance of pre-graphitic structure of PAN fibers at $2 \theta$ of $\sim 25.6^{\circ}$ due to stabilization. It was suggested that structural change by stabilization resulted in the significant decrease of tensile properties of fibers. From X-ray diffractograms of heat treated fibers, the pre-graphitic structure of stabilized fibers was developed to turbostratic structure. Furthermore, heat treatment up to $1200^{\circ} \mathrm{C}$ led to an increase of the integrated intensity ratio of the $D$ to $G$ bands, indicating the development of graphene layers. Tensile strength of fibers heat treated at $1200^{\circ} \mathrm{C}$ was found to be as high as $2.2 \mathrm{GPa}$.

\section{Acknowledgements}

This work was supported by a grant from Korea Institute of Science and Technology Institutional program and the Fundamental R\&D Program for Core Technology of Materials funded by the Ministry of Knowledge Economy, Republic of Korea.

\section{REFERENCES}

[1] J. D. Buckley and D. D. Edie, "Carbon-Carbon Materials and Composites," NASA Reference Publication 1254, 1992.

[2] M. K. Seo, S. H. Park, S. H. Kang and S. J. Park, "Carbon Fibers (III): Recent Technical and Patent Trends," Carbon Letters, Vol. 10, No. 1, 2009, pp. 43-51.

[3] A. Koganemaru, Y. Bin, Y. Agari and M. Matsuo, "Com- posites of Polyacrylonitrile and Multiwalled Carbon Nanotubes Prepared by Gelation/Crystallization from Solution," Advanced Functional Materials, Vol. 14, No. 9, 2004, pp. 842-850. doi:10.1002/adfm.200305034

[4] E. Fitzer, W. Frohs and M. Heine, "Optimization of Stabilization and Carbonization Treatment of PAN Fibers and Structural Characterization of the Resulting Carbon Fibers," Carbon, Vol. 24, No. 4, 1986, pp. 387-395. doi:10.1016/0008-6223(86)90257-5

[5] J. Kim, Y. C. Kim, W. Ahn and C. Y. Kim, "Reaction Mechanisms of Polyacrylonitrile on Thermal Treatment," Polymer Engineering \& Science, Vol. 33, No. 22, 1993, pp. 1452-1457. doi:10.1002/pen.760332203

[6] A. Yamane, D. Sawai, T. Kaneda, T. Kanemoto, M. Ito and R. S. Porter, "Development of High Ductility and Tensile Properties upon Two-Stage Draw of Ultrahigh Molecular Weight Poly(Acrylonitrile)," Macromolecules, Vol. 30, No. 14, 1997, pp. 4170-4178. doi:10.1021/ma9614095

[7] S. Lee, J. Kim, B. C. Ku, J. Kim and Y. Chung, "Effect of Process Condition on Tensile Properties of Carbon Fiber," Carbon Letters, Vol. 12, No. 1, 2011, pp. 26-30. doi:10.5714/CL.2011.12.1.026

[8] Q. Ouyang, L. Cheng, H. Wang and K. Li, "Mechanism and Kinetics of the Stabilization Reactions of Itaconic Acid-Modified Polyacrylonitrile," Polymer Degradation and Stability, Vol. 93, No. 8, 2008, pp. 1415-1421. doi:10.1016/j.polymdegradstab.2008.05.021

[9] I. Shimada and T. Takahagi, "FT-IR Study of the Stabilization Reactions of Polyacrylonitrile in the Production of Carbon Fibers," Journal of Polymer Science Part A: Polymer Chemistry, Vol. 24, No. 8, 1986, pp. 1989-1995.

[10] T. Takahagi, I. Shimada, M. Fukuhara, K. Morita and A. Ishitani, "XPS Studies on the Chemical Structure of the Stabilized Polyacrylonitrile Fiber in the Carbon Fiber Production Process," Journal of Polymer Science Part A: Polymer Chemistry, Vol. 24, No. 11, 1986, pp. 31013107.

[11] S. Dalton, F. Heatley and P. M. Budd, "Thermal Stabilization of Polyacrylonitrile Fiber," Polymer, Vol. 40, No. 20, 1999, pp. 5531-5543. doi:10.1016/S0032-3861(98)00778-2

[12] T. J. Xue, M. A. McKinney and C. A. Wilkie, "The Thermal Degradation of Polyacrylonitrile," Polymer Degradation and Stability, Vol. 58, No. 1-2, 1997, pp. 193-202. doi:10.1016/S0141-3910(97)00048-7

[13] Y. Zhu, M. A. Wilding and S. K. Mukhopadhyay, "Estimation, using Infrared Spectroscopy, of the Cyclization of Poly(Acrylonitrile) during the Stabilization Stage of Carbon Fibre Production," Journal of Materials Science, Vol. 31, No. 14, 1996, pp. 3831-3837. doi:10.1007/BF00352799

[14] A. Gupta and I. R. Harrison, "New Aspects in the Oxidative Stabilization of PAN-Based Carbon Fibers," Carbon, Vol. 34, No. 11, 1996, pp. 1427-1445. doi:10.1016/S0008-6223(96)00094-2

[15] P. Bajaj, T. V. Screekumar and K. Sen, "Thermal Behavior of Acrylonitrile Copolymers Having Methacrylic and Itaconic Acid Comonomers," Polymer, Vol. 42, No. 4, 
2001, pp. 1707-1718. doi:10.1016/S0032-3861(00)00583-8

[16] N. Chatterjee, S. Basu, K. Palit and M. M. Maiti, "XRD Characterization of the Thermal Degradation of Polyacrylonitrile," Journal of Polymer Science Part B: Polymer Physics, Vol. 33, No. 12, 1995, pp. 1705-1712.

[17] R. B. Mathur, O. P. Bahl, J. Mittal and K. C. Nagpal, "Structure of Thermally Stabilized PAN Fibers," Carbon, Vol. 29, No. 7, 1991, pp. 1059-1061. doi:10.1016/0008-6223(91)90189-P

[18] A. Gupta and I. R. Harrison, "New Aspects in the Oxidative Stabilization of PAN-Based Carbon Fibers II," Carbon, Vol. 35, No. 6, 1997, pp. 809-818. doi:10.1016/S0008-6223(97)00025-0

[19] D. Li, H. Wang and X. Wang, "Effect of Microstructure on the Modulus of PAN-Based Carbon Fibers during
High Temperature Treatment and Hot Stretching Graphitization," Journal of Materials Science, Vol. 42, No. 12, 2007, pp. 4642-4649. doi:10.1007/s10853-006-0519-4

[20] N. Keller, N. I. Maksimova, V. V. Roddatis, M. Schur, G. Mestl, Y. V. Butenko, V. L. Kuznetsov and R. Schlogl, "The Catalytic Use of Onion-Like Carbon Materials for Styrene Synthesis by Oxidative Dehydrogenation of Ethylbenzene," Angewandte Chemie International Edition, Vol. 41, No. 11, 2002, pp. 1885-1888. doi:10.1002/1521-3773(20020603)41:11<1885::AID-AN $\underline{\text { IE1885>3.0.CO;2-5 }}$

[21] N. Melanitis, P. L. Tetlow and C. Galiotis, "Characterization of PAN-Based Carbon Fibres with Laser Raman Spectroscopy," Journal of Materials Science, Vol. 31, No. 4, 1996, pp. 851-860. doi:10.1007/BF00352882 